them to be easily reflected or transmitted. From the time it was first proposed, the suggestion had few passionate supporters and has often been described as obscure or strange. As the editor of Newton's Optical Papers and an authority on the history of light, Shapiro is well prepared to write a monograph on Newton's theory. Indeed, he does more, and we find not one but two monographs between the covers of this book. The first is a study of Newton's theory of coloured bodies, the second a survey of its reception, challenge and eventual transformation between 1704 and 1833 .

Those who want a more general introduction to Newton's Opticks can turn to Hall's All Was Light, which captures both the intellectual daring and the experimental genius of Newton. Hall offers a detailed reconstruction of the development of Newton's investigation of light from the seminal period around 1666 when he discovered that sunlight consists of a mixture of rays of different colours that differ in refrangibility, the red ones less refracted than the violet at the other end of the spectrum. Soon afterwards, Newton discovered a method for measuring the thickness at which colours appear in a thin film. This discovery of what were afterwards called 'Newton's rings' was communicated to the Royal Society in 1675 but not set out fully until the publication of his Opticks in 1704.

The care and patience with which Newton carried out his experiments give us the measure of the man. He placed a lens of known curvature on a flat piece of glass and observed the coloured rings that appeared when he looked through the lens. Using an ordinary compass and the naked eye, he recorded one circle at $231 / 2$ hundredths of an inch in diameter and the next at $341 / 3$. When a small discrepancy appeared in his results, he relentlessly stalked the source until he found that the two faces of his lens had slightly different curvatures. The difference corresponded to a measurement of less than onehundredth of an inch in the diameter of the inner circle and about two onehundredths in the diameter of the sixth. Such were Newton's exacting standards of accuracy.

William R. Shea is at the Centre for Medicine, Ethics and Law at McGill University, Montreal, Quebec, Canada H3A 1W9.

A. Rupert Hall has also recently written a biography of Newton, Isaac Newton, Adventurer in Thought (Blackwell, 1992). It was reviewed in Nature 363, 29 (1993).

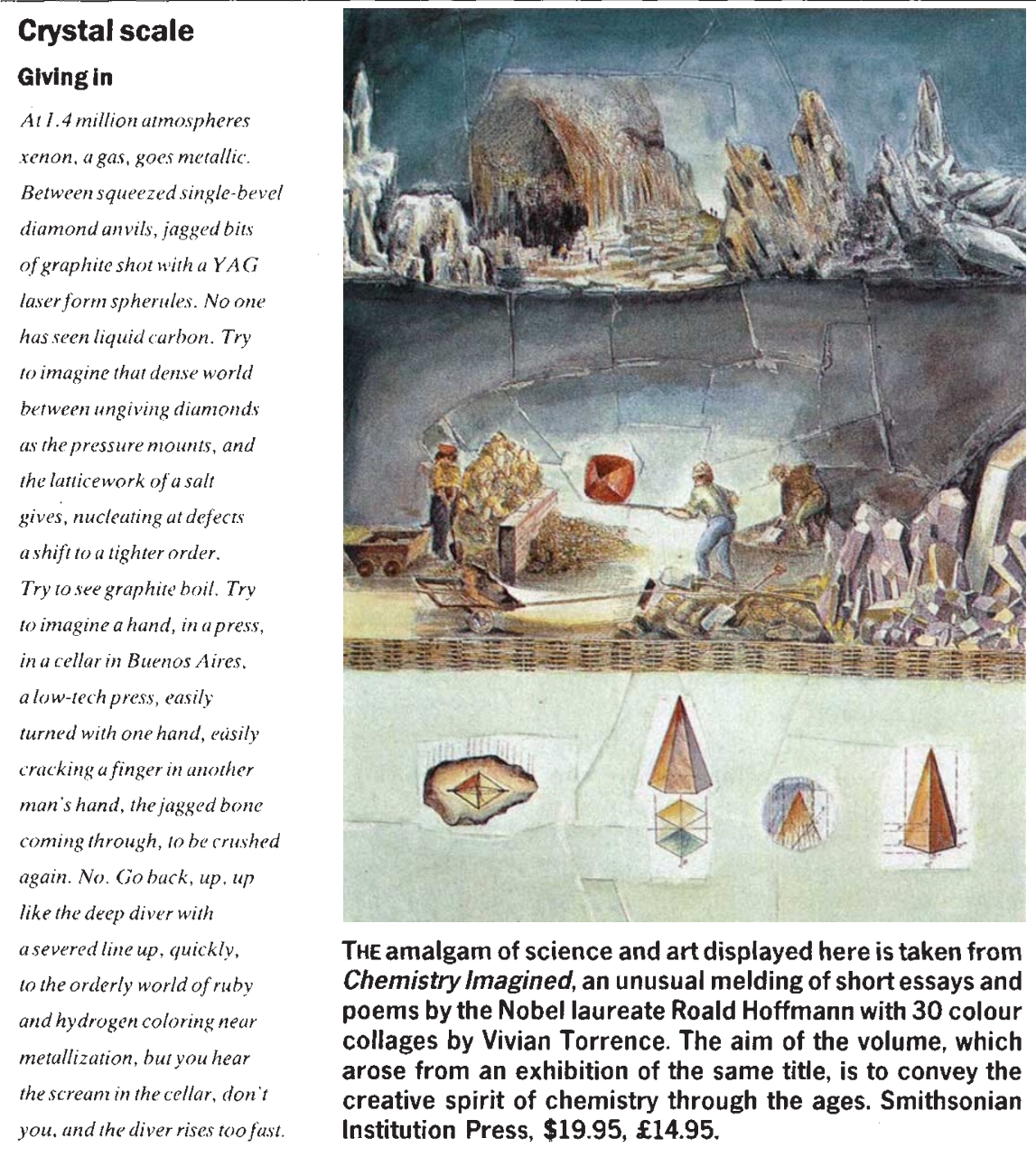

\section{Manufacturing knowledge}

\section{Stuart Blume}

Making Science: Between Nature and Society. By Stephen Cole. Harvard University Press: 1992. Pp. 290. \$39.95, $£ 31.95$.

WHEN the sociology of science emerged in the $1960 \mathrm{~s}$ as an area of professional sociological inquiry, it did so in sharp distinction to the existing discipline of history and philosophy of science. The content of science, scientific knowledge, was seen as principally a consequence of the organization of the natural world and hardly subject to sociological investigation. Questions of the genesis and status of facts and theories were matters for historians and philosophers. Inspired principally by the dominating figure of Robert K. Merton (professor of sociology at Columbia University), sociologists set out to investigate clearly social aspects of the behaviour of scientists and the functioning of scientific institutions. Merton had argued long before that certain 'norms' governed the way in which scientists collectively behaved. Many of his students addressed their research to the empirical consequences of Merton's ideas: for example, how far did scientists in practice evaluate one another's work purely in terms of its inherent scientific worth? One of these students, now himself a professor of sociology, was Cole.

A good example of the work done in this tradition was a study of the working of the peer review system at the National Science Foundation which Cole and others carried out in the mid-1970s. Reviewing 'phase 1' of this study in Nature 287, 807 (1980) I wrote: "An effective combination of statistical and qualitative analysis is used to show, most simply, that the best research gets funded. No evidence for an old boy network is uncovered, and the findings suggest that referees are not much influenced by the status of the applicant's institutional affiliation, or by his seniority. They simply judge the application on its merits". But by the time this study (and my review) was published, sociologists, influenced by the work of Kuhn, were starting to ask quite different questions about science.

Sociologists began to articulate a sociology of scientific knowledge, in which scientific theories and methods were no longer to be viewed as uniquely related to the nature of the natural world. The statements articulated and advanced by scientists began to be viewed as products of the social processes through which articulation and so on took place. A new sociology of science was emerging, 